\title{
Health Assessment of Radiant Heater Tube
}

\author{
Ashok Kumar Ray, Yogendra Nath Tiwary, Abdul Jabbar Khan*, Prabir Kumar Roy, \\ Gautam Das and Raghubir Singh \\ National Metallurgical Laboratory (CSIR), Jamshedpur-831007, India \\ ${ }^{*}$ R\&D Division, Tata Iron \& Steel Company, Jamshedpur-831 007, India
}

(Received April 8, 2004; final form June 14, 2004)

\begin{abstract}
A radiant heater tube in an oil refinery made of a particular grade of austenitic steel and service exposed for 61,000 hours was investigated for health assessment and safety. Experimentally determined yield strength and ultimate tensile strength as well as estimated 10,000 hours $-100,000$ hours rupture strength as obtained from experimental data in the temperature range of 773 to 873K exhibit a decreasing trend with increasing temperature. Microstructural study did not reveal any significant degradation in terms of creep cavities, cracks, graphitization etc. Analysis of hot tensile and accelerated stress rupture data revealed that the service exposed radiant heater tube could remain in service for a length of more than ten years at the operating hoop stress level and maximum allowable skin temperature (158.78 MPa / $865 \mathrm{~K})$, provided no localised damage in the form of cracks or dents had developed. It is recommended that a similar health check of these tubes should be carried out after 50,000 hours of service exposure at the desired operating conditions.
\end{abstract}

Key words: Radiant heater tube, austenitic steel, service exposed, strength, rupture, creep, cracks, stress level., health, safety.

\section{INTRODUCTION}

The consequence of any service failure can be tragic and expensive. There are many cases of engineering disasters resulting in loss of life and property. For oil refinery and boiler components, the utmost attention is a must to ensure that such incidents do not take place. Life assessment exercise performed at regular intervals is a means to ensure the prevention of such tragic service failures.

Carbon and $\mathrm{Cr}$-Mo steels are extensively used as high temperature components in oil refineries and power plants $/ 1-10 /$. Even though most of these components have a specific design life of 20 years, many of these are known to have survived much longer. Health assessment of these components is best estimated by conducting a systematic life assessment exercise during a planned plant shutdown. In most cases, damage accumulation starts from the outer surface. It manifests itself as surface cracks. Therefore, careful visual examination and non-destructive tests (e.g. Dye penetration tests, Magnetic Particle Inspection etc.) carried out on the outer surface can give a fair idea about the health of the component. In addition, the use of an ultrasonic flaw detector can also detect defects within the material. In view of the increasing cost of setting up a new plant, there is now considerable interest in life extension of the existing units. In order to arrive at a quantitative estimate of the remaining life of such ageing components, it is necessary to have some hot tensile, creep and stress rupture data for service exposed tubes at high temperature.

\subsection{Brief history}

The Vacuum Reboiler Furnace is a balanced draft box type furnace with air-heat system. The tubes are installed horizontally with return bends within the 
firebox. The furnace is designed for a heat duty of $0.0106-\mathrm{mm} \mathrm{KJoule} / \mathrm{sec}$. The furnace maintains the bottom temperature of the Vacuum Column. The hot feed from the Vacuum Column enters the convection section in four passes at an inlet temperature of $649 \mathrm{~K}$ and goes to the Vacuum Column at an outlet temperature of $663 \mathrm{~K}$. The firing temperature is mixed type with fuel oil and fuel gas. No thickness loss was recorded for the tubes since the last installation and hence no replacement was called for. Vibration of radiant coils was experienced after commissioning. Four number tubes in each pass were cut and re-welded after providing cold pull in 1995. Ultrasonic flaw detection, outer diameter gauging and die penetrant checks during shutdowns did not reveal any defects till date. Coking is a possibility in the heater during operation However, decoking operation at 3-4 year intervals is undertaken and no deposits in the internal surface of the tubes were observed by the plant workforce.

During the last turnaround, one radiant heater tube of diameter 168 and $6.22 \mathrm{~mm}$ thick was taken out for health assessment. The service history and material specification of the radiant heater tube are shown in Table 1.

Table 1

Material specification and service history

\begin{tabular}{|l|l|}
\hline Location & $\begin{array}{l}\text { Vacuum Reboiler Heater 06- } \\
\text { FF-004 of Hydrocracker Unit }\end{array}$ \\
\hline Commissioned & 1994 \\
\hline Grade of steel & A271 TP 321 \\
\hline Size & $\begin{array}{l}168.275 \mathrm{~mm} \text { (outer diameter) } \\
\times 6.22 \mathrm{~mm} \text { (thickness) } \times 6634 \\
\mathrm{~mm}(\text { length) }\end{array}$ \\
\hline $\begin{array}{l}\text { Maximum allowable } \\
\text { skin temperature }\end{array}$ & $865 \mathrm{~K}$ \\
\hline $\begin{array}{l}\text { Temperature of the } \\
\text { hot feed at the } \\
\text { vacuum column } \\
\text { outlet }\end{array}$ & $663 \mathrm{~K}$ \\
\hline Operating pressure & $140000 \mathrm{~kg} / \mathrm{m}^{2}(\mathrm{~g})$ \\
\hline
\end{tabular}

\section{METHODOLOGY}

\subsection{Visual examination and dimensional measurement}

One half of the tube was yellowish grey and rough along the length and the remaining half was dark brown and smooth. The smooth and dark brown portion is the region that is exposed to the highest temperature facing the burners. In the present investigation, all test samples were fabricated from this region only. The pictorial view of the radiant heater tube to be investigated for remaining life assessment is shown in Fig.l.

Dimensions of the outer diameter (OD) were measured at two mutually perpendicular directions along the length of the tube at an interval of $150 \mathrm{~mm}$.

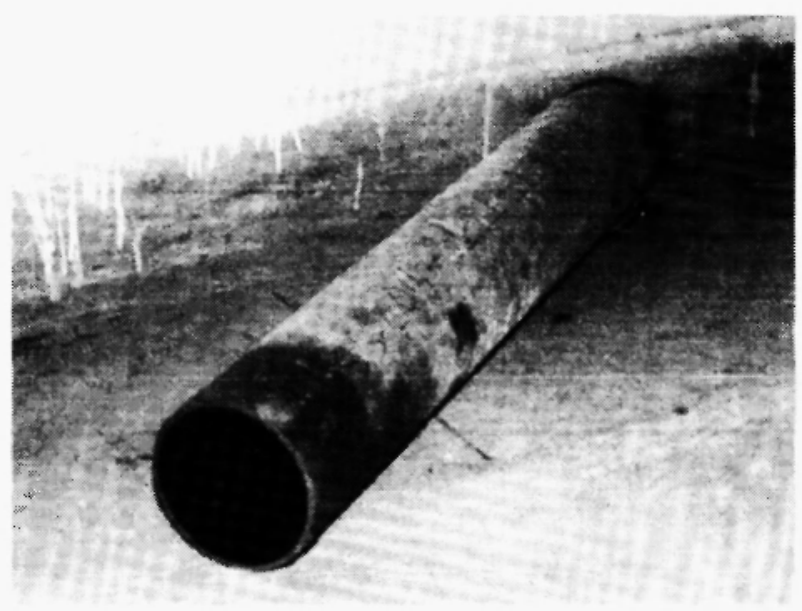

Fig. 1: Pictorial view of the radiant heater tube to be investigated for remaining life assessment.

\subsection{Chemical analysis by wet method}

Chemical analysis of the service exposed tube material under the present investigation was carried out by the standard wet method.

\subsection{Metallography}

Optical metallographic examinations were carried out on the service exposed tube both in the longitudinal as well as in the short transverse direction of the service exposed tube. The etchant used was $2 \%$ nital solution. 


\subsection{EDAX analysis by SEM. (Scanning Electron Microscope)}

The EDAX analysis was carried out on the stringers of precipitates in order to understand the morphology of the carbides.

\subsection{Tensile tests}

Tensile tests at room temperature (298K), 623K, $723 \mathrm{~K}, 823 \mathrm{~K}$ and at $873 \mathrm{~K}$ of the service exposed radiant heater tube were performed using a digitally controlled 8562 Instron servo-electric testing system, equipped with a 3-zone split furnace with PID control. Standard tensile specimens were made from the service-exposed materials as per ASTM E8-79 specification. Tensile tests were carried out on the base metal only from the longitudinal direction of the service exposed tube. During tensile test, constant test temperature within $\pm 275 \mathrm{~K}$ and a constant displacement rate of \pm 0.2 $\mathrm{mm} / \mathrm{min}$ were maintained.

\subsection{Accelerated stress rupture tests}

Accelerated stress rupture tests using constant load Mayes creep testing machines were carried out as per ASTM 139/83 specification with flat specimens made from the longitudinal direction of the service-exposed radiant heater tube. These tests were carried out in the temperature range of $873-973 \mathrm{~K}$ and in the stress range of 54.6-160 MPa. The stress levels above the operating stress at each temperature were selected in such a way as to obtain rupture within a reasonable span of time. The hoop stress $\sigma_{h}$ acting on the service- exposed radiant heater tube was calculated using the following formula:

$$
\sigma_{\mathrm{h}}=\mathrm{PD} / 2 \mathrm{t}
$$

where $\mathrm{P}$ is the operating pressure in $\mathrm{MPa}, \mathrm{D}$ is the mean diameter in $\mathbf{m m}$ and $\mathrm{t}$ is the thickness of the tube in $\mathbf{m m}$. The operating hoop stress thus evaluated is $\sim 158.78$ $\mathrm{MPa}$.

An estimate of the remaining life at the operating hoop stress and temperature is then made by analysis of the creep rupture data using Larson-Miller Parameter (LMP) which is defined as follows:

$$
\mathrm{LMP}=\mathrm{T}\left(15+\log \mathrm{t}_{\mathrm{r}}\right)
$$

where $\mathrm{T}=$ Temperature in Rankine as per API RP 530 specification and $\mathbf{t}_{\mathbf{T}}=$ Rupture time in hours

The life in hours of the service-exposed tube was then estimated at various temperatures from the LMP value. Regression analysis of stress rupture data for service-exposed radiant tube has been carried out using a standard software package, in order to evaluate the long term rupture strength of the tubes over a range of temperature.

$$
\begin{aligned}
& \text { Larson- Miller Parameter }(\text { LMP })=T\left(15+\log t_{r}\right) \\
& =a_{0}+a_{1}(\log S)+a_{2}(\operatorname{logS})^{2}+\ldots \ldots \ldots \ldots \ldots+ \\
& \\
& a_{m}(\log S)^{m}
\end{aligned}
$$

where

$\mathrm{S}=$ Rupture strength in $\mathrm{MPa}$

$\mathbf{m}=$ Order of polynomial

$a_{0}, a_{1} a_{2} \& a_{m}$ are polynomial constants.

\section{RESULTS AND DISCUSSION}

\subsection{Visual examination and dimensional measurement:}

The smooth and dark brown portion of the service exposed radiant tube is the region which is exposed to highest temperature facing the burners. There was no oxide scale deposition on the inner or outer surface of the tube. The dimensional measurement carried out on these tubes did not show any appreciable damage in OD (outer diameter), wall thickness and the cross sections of the service exposed tube were found to be of uniform thickness. There was no evidence of any localised attack on the outer and inner surfaces of the tube. The measured thickness and outer diameter (OD) of the tube were $7.1 \mathrm{~mm}$ and $169 \mathrm{~mm}$ respectively.

\subsection{Chemical Analysis:}

Chemical analysis as revealed in Table 2 shows that the material under the present investigation is basically austenitic grade of steel and it conforms to the grade specified. 
Table 2

Chemical composition of the heater tube material

\begin{tabular}{|l|c|c|c|c|c|c|c|c|}
\hline Material & \multicolumn{7}{|c|}{ Elements, mass\% } \\
\hline ASTM & $\mathrm{C}$ & $\mathrm{Cr}$ & $\mathrm{Ni}$ & $\mathrm{Mo}$ & $\mathrm{N}$ & $\mathrm{Nb}$ & $\mathrm{Ti}$ & $\mathrm{Fe}$ \\
\cline { 2 - 8 } A 271 & 0.035 & 2.52 & 1.12 & - & - & - & 0.089 & Balance \\
T:P 321 & & & & & & & & \\
\hline
\end{tabular}

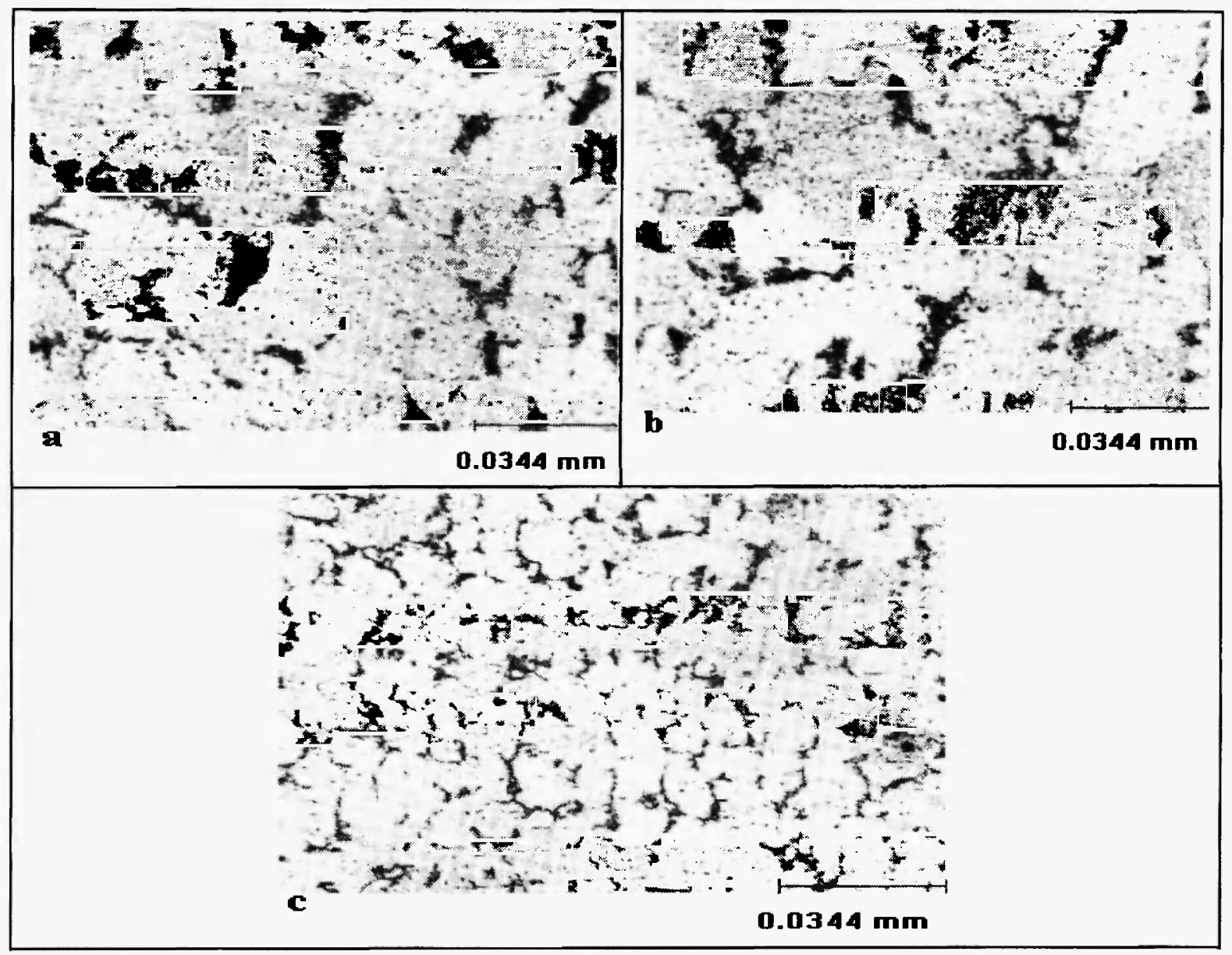

Fig. 2 (a, b \& c): Optical micrographs of the radiant heater tube in the transverse direction of the tube and at different locations showing precipitation of titanium carbides (confirmed from EDAX analysis) along the austenitic grain boundaries. Precipitation within the austenitic grains primarily consists of chromium carbides as confirmed by EDAX. (a \& b) are at a magnification of X600 and (c ) is at a magnification of $\mathrm{X} 300$.

\subsection{Metallography:}

Optical metallographic examinations were carried out on the service-exposed tubes. The microstructure mainly consisted of austenitic grains with carbide precipitation within and at the grain boundaries in the short transverse direction of the tube (see Fig. 2). Several annealing twins and stringers of carbide precipitates aligned in one particular direction (possibly the rolling direction) was also observed in the longitudinal direction of the tube (see Fig. 3a \& 3b). Therefore, it is clear that the service exposed radiant heater tube has had hardly any appreciable degradation from the microstructural point of view. Fig. 4 reveals the optical metallograph of the creep ruptured specimen at $112 \mathrm{MPa} / 923 \mathrm{~K}$, where creep, cavitation voids were 


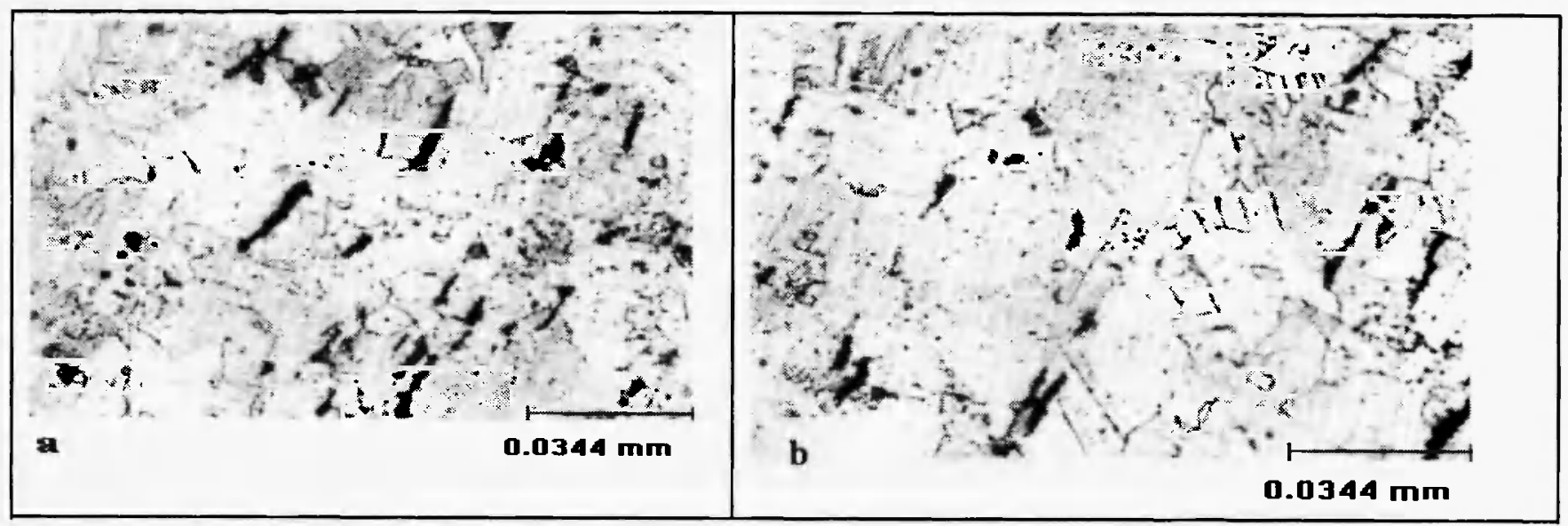

Fig. 3: (a \& b): Optical micrographs of the radiant heater tube taken at different locations in the longitudinal direction of the tube revealing stringers of $\mathrm{Ti}(\mathrm{C}, \mathrm{N})$ and chromium carbides aligned in one particular direction (could be the rolling direction). A lot of annealing twins are seen. Precipitation within the austenitic grains primarily consists of chromium carbides as confirmed by EDAX. The micrographs are taken at a magnification of $\mathrm{X} 600$.

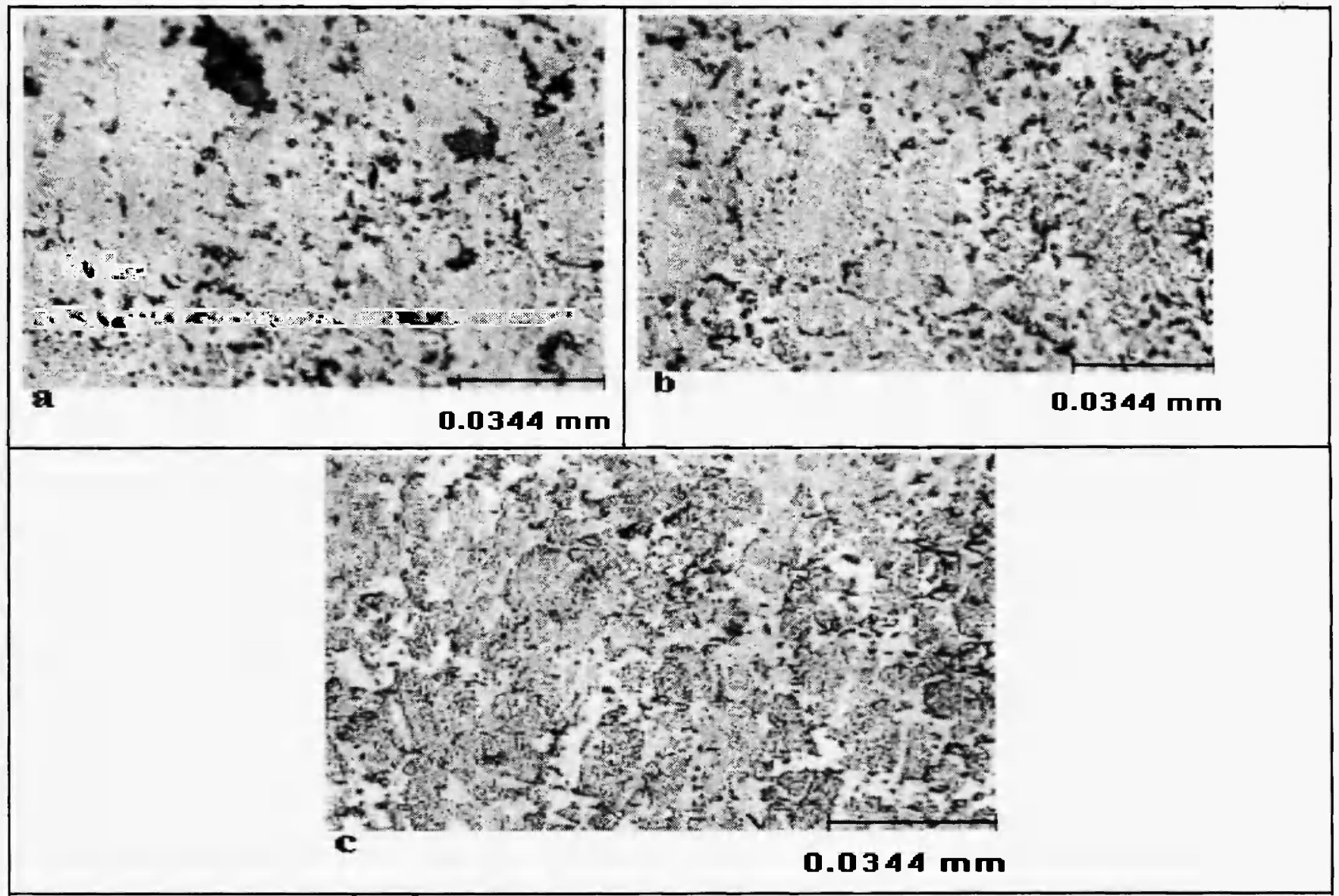

Fig.4: (a \& b). Creep cavitation voids formed due to microvoid coalescence at the grain boundaries in the creep rupture sample near the fracture surface, at different locations and at a magnification of X600.

(c) Creep cavitation voids formed due to microvoid coalescence at the grain boundaries in the creep rupture sample away from the fracture surface taken at a magnification of $\mathrm{X} 600$. 
observed near the fracture surface (see Fig. 4a). Creep cavitation damage due to microvoid coalescence at the grain boundaries of the creep-ruptured sample was also revealed (see Fig. $4 b \&$ c).

To reveal the morphology of the carbides, the carbides along the grain boundaries were resolved at very high magnification in the Scanning Electron Microscope (JEOL $840 \mathrm{~A}$ ). These primarily consisted of Ti $(\mathrm{C}, \mathrm{N})$, which were confirmed from EDAX analysis.
The morphology of $\mathrm{Ti}(\mathrm{C}, \mathrm{N})$ at the grain boundary is revealed in Fig.5a and its EDAX analysis has been reported in Fig.5b. Fig.5c. shows the morphology of the matrix precipitates. The precipitation in the matrix within the austenitic grains comprised of both $\mathrm{Ti}(\mathrm{C}, \mathrm{N})$ as well as chromium carbides as was confirmed from EDAX analysis (see Fig. 5d). Within the stringers of carbides aligned in a particular direction of the tube (in the longitudinal direction), a substantial amount of
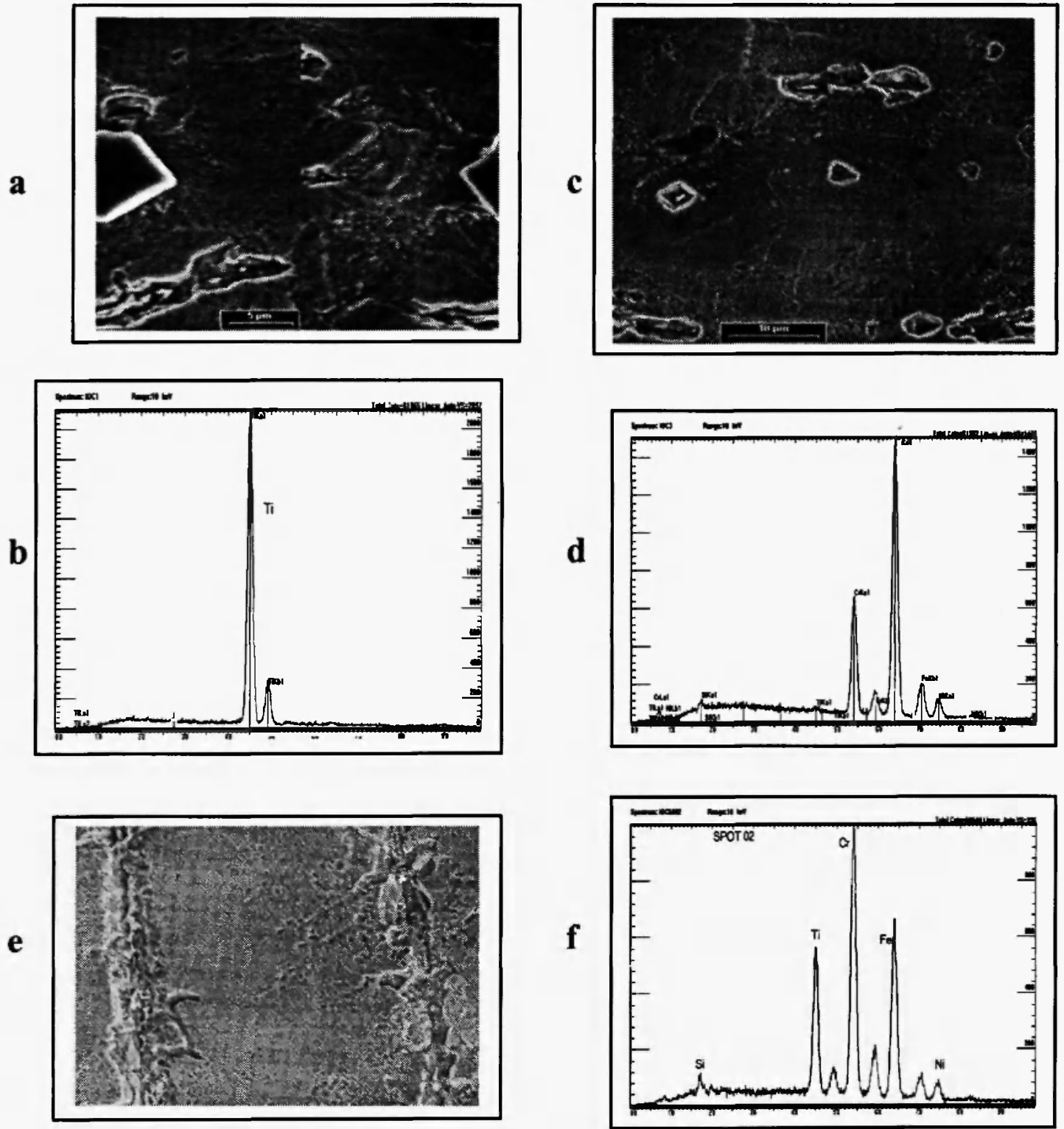

Fig 5: (a) Morphology of $\mathrm{Ti}(\mathrm{C}, \mathrm{N})$ at the grain boundary with its EDAX analysis. (b). (c ) shows the morphology of the matrix precipitates with their EDAX analysis. (d). (e) shows morphology of the Ti (C,N) and chromium carbide precipitates at spot 2 on the stringers of precipitates in the sample observed in the longitudinal direction of the tube with its EDAX analysis (f). 
Table3

EDAX analysis of the precipitates taken at various locations in Fig.5e.

\begin{tabular}{|c|c|c|c|c|c|c|c|}
\hline Location & $\mathbf{A l}(\mathbf{K} \alpha)$ & $\mathrm{Si}(\mathrm{K} \alpha)$ & $\mathrm{Ti}(\mathrm{K} \alpha)$ & $\mathbf{C r}(\mathbf{K} \alpha)$ & $\mathbf{M n}(\mathbf{K} \alpha)$ & $\mathbf{F e}(\mathbf{K} \alpha)$ & $\operatorname{Ni}(\mathbf{K} \alpha)$ \\
\hline Feature I & 0.00 & 0.29 & 0.18 & 17.02 & 1.79 & 71.05 & 9.67 \\
\hline Feature2 & 0.08 & 0.50 & 13.18 & 37.43 & 3.36 & 38.79 & 6.66 \\
\hline Feature3 & 0.00 & 0.25 & 0.34 & 16.56 & 2.14 & 70.04 & 10.68 \\
\hline Feature4 & 0.00 & 0.00 & 1.33 & 37.18 & 2.87 & 53.94 & 4.69 \\
\hline Feature5 & 0.00 & 0.00 & 1.16 & 17.45 & 2.82 & 71.71 & 6.86 \\
\hline Feature6 & 0.00 & 0.27 & 0.23 & 17.16 & 1.62 & 71.80 & 8.91 \\
\hline Feature7 & 0.00 & 0.19 & 1.01 & 29.32 & 2.59 & 59.96 & 6.94 \\
\hline Feature8 & 0.00 & 0.31 & 0.32 & 17.73 & 1.52 & 71.59 & 8.54 \\
\hline
\end{tabular}

chromium carbides were also present along with $\mathrm{Ti}$ $(C, N)$ as revealed from the SEM micrograph ( see Fig.5e at $X 1500$ ) and confirmed from EDAX analysis of the same ( Fig. $5 f$ ). The results of EDAX analysis of the precipitates taken at various locations in Fig.5e are tabulated in Table 3.

\subsection{Mechanical properties:}

Room temperature as well as high temperature tensile properties as obtained from experiments are reported in Fig. 6. The variation of yields strength $(0.2 \%$ proof stress) with test temperature and that of ultimate tensile strength (UTS) with test temperature are shown in Figs. 6a. Fig. 6b shows the variation of \% El (Elongation) with test temperature. It is evident that $0.2 \%$ proof stress (yield strength) and the UTS (ultimate tensile strength) values for the service exposed tubes showed a decreasing trend with increasing temperature. However, \% El (Elongation) showed an increasing trend with temperature. This is the common trend observed for materials tested at elevated temperature $/ 4-10 \%$. The fall in ductility from room temperature to $623 \mathrm{~K}$ is due to blue brittleness in these materials.

In the absence of discernible cavitation or flaws, stress rupture tests can be selectively used to assess the condition of components. One of the most widely used techniques for life assessment of components involves removal of samples from the region which is exposed to highest temperature and conducting accelerated tests at temperatures above the service temperature $/ 7 \%$. An

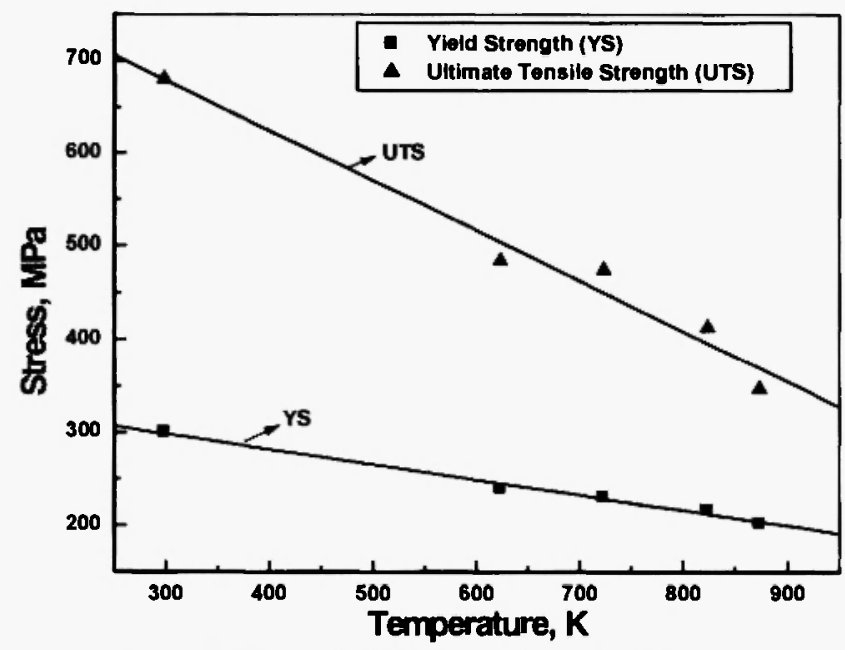

Fig. 6a:Variation of yield strength and ultimate tensile strength for the service exposed radiant heater tube.

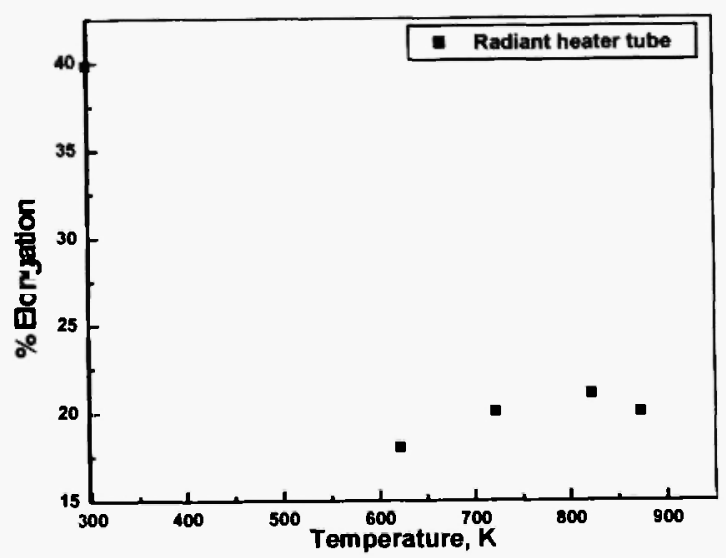

Fig. 6b: Variation of $\%$ elongation with test temperature for the service exposed radiant heater tube. 
estimate of the remaining life is then made at the operating hoop stress and temperature by analysis of the creep rupture data using Larson-Miller Parameter (LMP) and by extrapolation of the results to the service temperature. Several uncertainties relating to the validity and application of the technique have been resolved in recent research projects $/ 7 /$.

The experimentally determined stress rupture data for the service-exposed radiant heater tube are reported in Table 4 and the polynomial constants in regression analysis of the stress rupture data are shown in Table 5. The data obtained from short term stress rupture tests of the service exposed radiant heater tube have been compared with the reported data on virgin material pertaining to the same grade of steel as per API RP 530, (Fig. 7). The lines in the figure represents the mean and minimum rupture strength for the virgin material of the same steel from literature (API RP 530 data line). It is clear that all the data fall on or above the minimum API RP 530 data line. It is noteworthy that at low stress

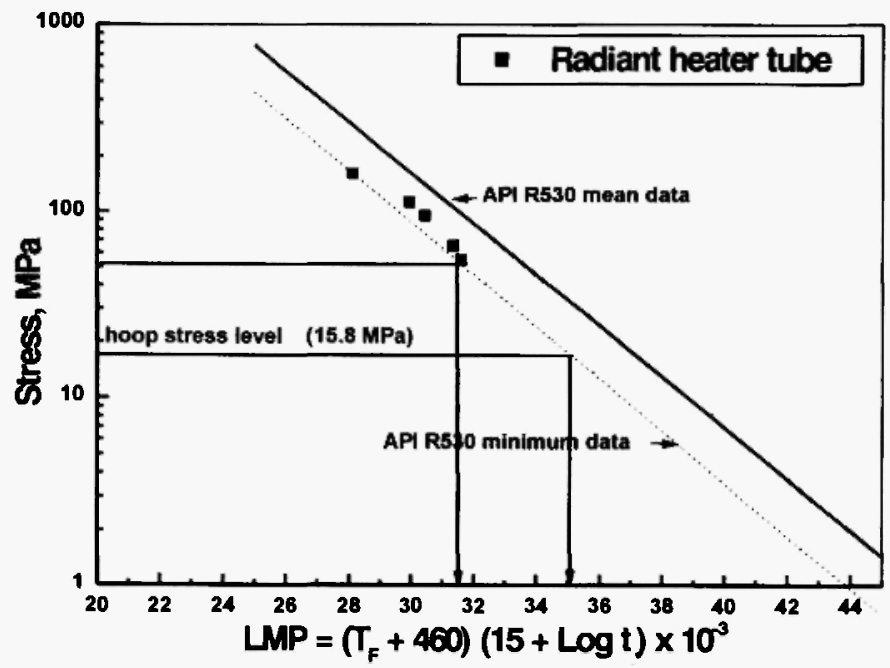

Fig. 7: Plot of stress versus LMP (Larson Miller Parameter) for the service exposed radiant heater tube.

levels the stress rupture data do merge with the minimum API RP 530 data line which is the common

Table 4

Stress rupture data of the service exposed radiant heater tube

\begin{tabular}{|c|c|c|c|c|}
\hline $\begin{array}{c}\text { Temp, } \\
(\mathbf{K})\end{array}$ & $\begin{array}{c}\text { Stress, } \\
(\mathbf{M P a})\end{array}$ & $\begin{array}{c}\text { Expected Rupture } \\
\text { Time as per API } \\
\text { RP 530 } \\
\text { Specification, } \\
\text { (hours) }\end{array}$ & $\begin{array}{c}\text { Rupture Time, } \\
\text { (hours) }\end{array}$ & $\begin{array}{c}\% \\
\text { Elongation }\end{array}$ \\
\hline 973 & 65.1 & 500 & 816 (interrupted) & - \\
\hline 973 & 54.6 & 1000 & 1152 (interrupted) & - \\
\hline 923 & 94.5 & 2000 & 2184 (interrupted) & - \\
\hline 923 & 112.0 & 1000 & 1080 (ruptured) & 27.10 \\
\hline 873 & 160 & 800 & 808 (interrupted) & - \\
\hline
\end{tabular}

Table 5

Polynomial constants from regression analysis

\begin{tabular}{|c|c|c|c|c|c|}
\hline $\begin{array}{c}\text { Type of } \\
\text { service } \\
\text { exposed } \\
\text { material }\end{array}$ & $\begin{array}{c}\text { Order of } \\
\text { polynomial }\end{array}$ & $\begin{array}{c}\text { Average } \\
\text { sum square } \\
\text { error }\end{array}$ & $\mathbf{a}_{0}$ & $\mathbf{a}_{1}$ & $\mathbf{a}_{2}$ \\
\hline $\begin{array}{l}\text { Radiant } \\
\text { heater tube }\end{array}$ & $\mathrm{m}=2$ & $\begin{array}{c}0.3171503 \\
\times 10^{2}\end{array}$ & $\begin{array}{c}0.32822369 \\
\times 10^{5}\end{array}$ & -17.604991 & -0.0722683 \\
\hline
\end{tabular}


Table 6

Estimated rupture strength $(\mathrm{S})$ of the service exposed radiant heater tube.

\begin{tabular}{|c|c|c|c|c|c|}
\hline \multirow{2}{*}{$\begin{array}{l}\text { Type of service exposed } \\
\text { material }\end{array}$} & \multirow{2}{*}{$\begin{array}{c}\text { Temp, } \\
\mathbf{K}\end{array}$} & \multirow{2}{*}{$\begin{array}{c}\text { Order of } \\
\text { Polynomial }\end{array}$} & \multicolumn{3}{|c|}{ Time $\left(t_{r}\right)$ in hrs } \\
\hline & & & 10,000 & 30,000 & 100,000 \\
\hline \multirow[t]{9}{*}{ Radiant heater tube } & 773 & $\mathrm{~m}=2$ & $\mathrm{~S}=360.5 \mathrm{MPa}$ & $\mathrm{S}=323 \mathrm{MPa}$ & $\mathrm{S}=281.8 \mathrm{MPa}$ \\
\hline & 823 & $\mathrm{~m}=2$ & $\mathrm{~S}=263.8 \mathrm{MPa}$ & $\mathrm{S}=223.8 \mathrm{MPa}$ & $\mathrm{S}=180 \mathrm{MPa}$ \\
\hline & 865 & $\mathrm{~m}=2$ & $\mathrm{~S}=182.6 \mathrm{MPa}$ & $\mathrm{S}=140.6 \mathrm{MPa}$ & $\mathrm{S}=94.5 \mathrm{MPa}$ \\
\hline & 873 & $\mathrm{~m}=2$ & $\mathrm{~S}=167.1 \mathrm{MPa}$ & $\mathrm{S}=124.7 \mathrm{MPa}$ & $\mathrm{S}=78.2 \mathrm{MPa}$ \\
\hline & 773 & $m=1$ & $\mathrm{~S}=214.0 \mathrm{MPa}$ & $\mathrm{S}=194.3 \mathrm{MPa}$ & $\mathrm{S}=172.3 \mathrm{MPa}$ \\
\hline & 823 & $m=1$ & $\mathrm{~S}=162.7 \mathrm{MPa}$ & $\mathrm{S}=141.4 \mathrm{MPa}$ & $\mathrm{S}=118 \mathrm{MPa}$ \\
\hline & 865 & $m=1$ & $\mathrm{~S}=119.3 \mathrm{MPa}$ & $\mathrm{S}=96.8 \mathrm{MPa}$ & $\mathrm{S}=72.3 \mathrm{MPa}$ \\
\hline & 873 & $\mathrm{~m}=1$ & $\mathrm{~S}=111.0 \mathrm{MPa}$ & $\mathrm{S}=88.41 \mathrm{MPa}$ & $\mathrm{S}=63.6 \mathrm{MPa}$ \\
\hline & 923 & $\mathrm{~m}=1$ & $\mathrm{~S}=59.4 \mathrm{MPa}$ & $\mathrm{S}=35.5 \mathrm{MPa}$ & $\mathrm{S}=9.2 \mathrm{MPa}$ \\
\hline
\end{tabular}

trend observed in such steels. However, one can conclude that all the stress rupture data lie well within the scatter band of the API RP 530 mean data line (see Fig. 7). Therefore, as far as creep strength is concerned there is no appreciable degradation due to service exposure. This is also consistent with the information collected from other destructive and non-destructive tests conducted on similar components. Table 6 reveals the estimated rupture strength, $S$ of the service exposed tubes in the temperature range of $793 \mathrm{~K}$ to $853 \mathrm{~K}$, for various rupture times and at $m=I \& 2$. The variation of estimated rupture strength with temperature of the service-exposed radiant heater tube is revealed in Fig. 8. It is clear from Fig. 8 that the estimated $10,000-$ $100,000 \mathrm{hr}$. rupture strengths at various temperatures showed a decreasing trend with increasing temperature. This is the general trend observed in service-exposed materials /5,8-10/. A typical macro-photograph (Fig. 9) of a creep ruptured specimen shows that creep failure did occur within the gauge length portion of the specimens.

In the present investigation, long-term rupture strengths were estimated (see Table 6) with best-fitted curves for first and second order polynomials. For different orders of the polynomial, the average sum square error (ASSE) was estimated from the following equation:

$$
\text { ASSE }=\sum\left(Y_{\text {experimental }}-Y_{\text {estimated }}\right)^{\hat{z}} / n
$$

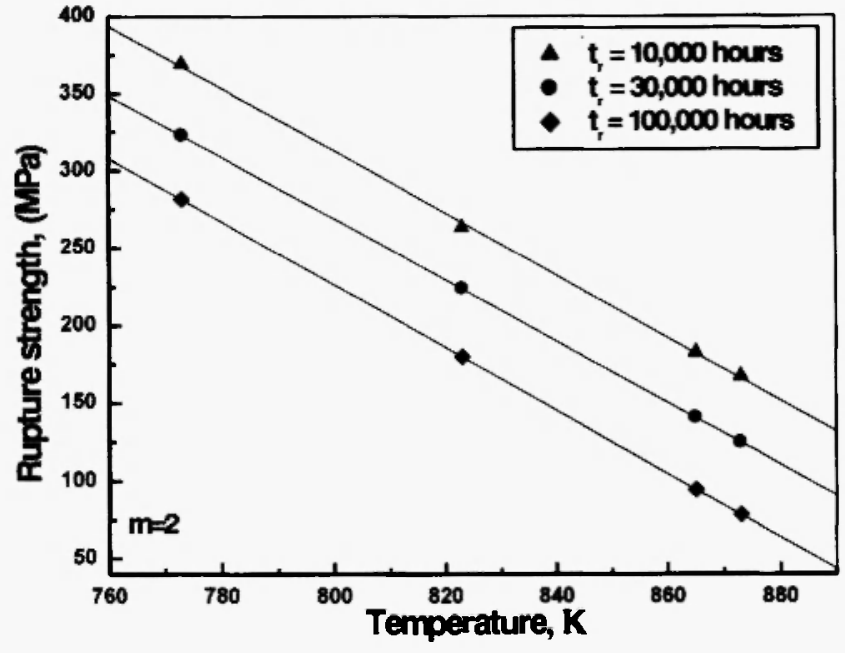

Fig. 8: Variation of estimated rupture strength with temperature for the service exposed radiant heater tube.

where $n$ is the number of data points. The second order polynomial $(m=2)$ was selected for estimation of rupture strength as there was no significant change in the average sum square error for higher orders.

Since microstructural examination of the as received sample did not show any major degradation like creep cavitation damage due to micro void coalescence, evidence of spheroidization/graphitization, decarburization etc., it is expected that the mechanical properties will be within expected limits, which is also revealed 


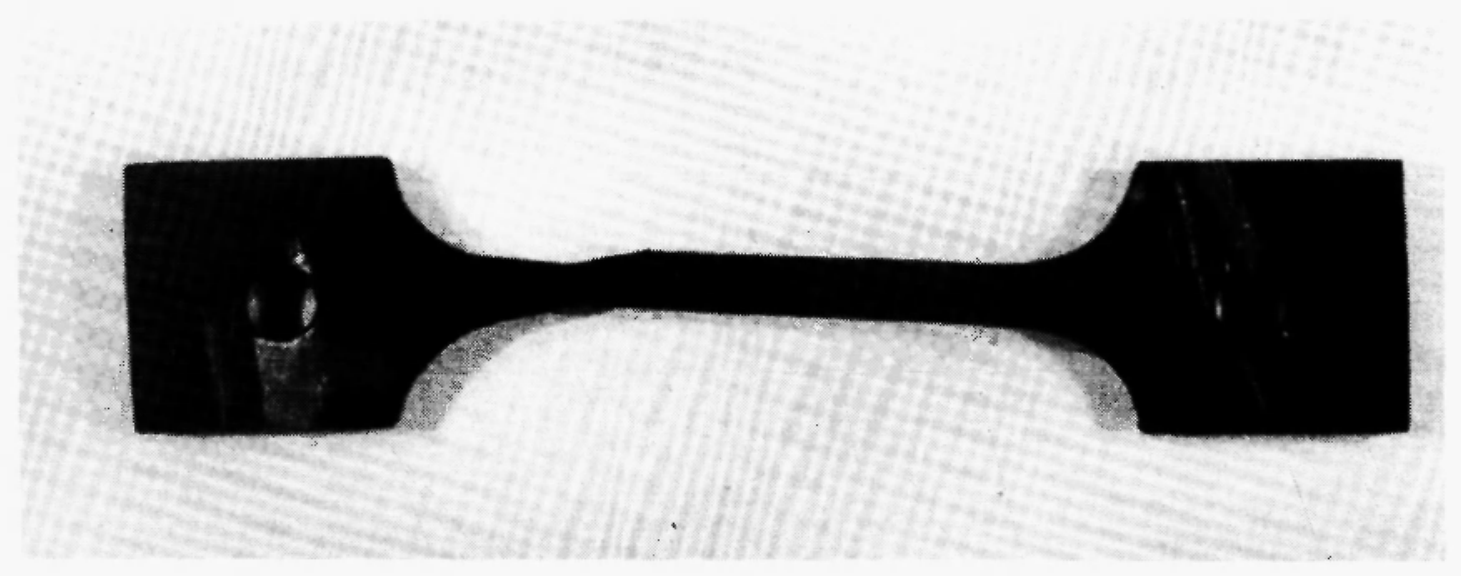

Fig. 9: Macro-photograph of an accelerated creep ruptured sample, tested at $112 \mathrm{MPa} / 923 \mathrm{~K}$.

from the experimental data. The remaining life of the service exposed tube in hours was then estimated at various temperatures, from the LMP value as read from Fig. 7. The estimated remnant lives of the service exposed radiant heater tube at the operating hoop stress and at two different temperature levels are tabulated in Table 7.

\section{Table 7}

Remaining life of the service exposed radiant heater tube

\begin{tabular}{|l|c|}
\hline Operating condition & Life in hours \\
\hline $773 \mathrm{~K} / 158.78 \mathrm{MPa}$ & $>2,000,00$ \\
\hline $865 \mathrm{~K} / 158.78 \mathrm{MPa}$ & $>1,00,000$ \\
\hline
\end{tabular}

Based on the stress rupture data, at the operating hoop stress level of $158.78 \mathrm{MPa}$ and at $865 \mathrm{~K}$ (maximum allowable skin temperature), it is possible to obtain a life of about more than 10 years, provided there is no off-shoot of temperature, the overload of the panel does not exceed the limit and that there is no evidence of localised damage in the form of surface cracks, cavitation or dents.

The service exposed radiant heater tube appears to be in a reasonably good state of health. Another check for safety of the service exposed tube in terms of residual life is recommended to be carried out after expiry of 50,000 hours of service life from the aspect of economical and safety reasons. Also during shut down of the plant, NDT (nondestructive) tests viz. dimensional (thickness and diameter) measurement, hardness measurement and in situ metallography need to be carried out to assess the condition of the materials for their future serviceability.

\section{CONCLUSION}

So far as the residual life at $865 \mathrm{~K}$ (maximum allowable skin temperature)/158.78 $\mathrm{MPa}$ is concerned, it is possible to obtain a minimum life of more than ten years for the service exposed radiant heater tube, provided there is no evidence of localised damage in the form of surface cracks, cavitation or dents, there is no off shoot of temperature and that the overload of the panel does not exceed the limit. Experimentally determined yield strength and ultimate tensile strength as well as estimated 10,000 hours $-100,000$ hours rupture strength as obtained from experimental data exhibit a decreasing trend with increasing temperature. The service exposed radiant heater tube appears to be in a reasonably good state of health. Another check for safety of the service exposed pipes in terms of residual life is recommended to be carried out after expiry of 50,000 hours of service life from the view of economical and safety reasons. Also during shut down of the plant, NDT (nondestructive) tests viz. dimensional (thickness and diameter) measurement, hardness measurement and in situ metallography may 
be carried out to assess the condition of the materials for their future serviceability.

\section{ACKNOWLEDGEMENT}

The authors are thankful to Mr. Sailender Kumar and Mr. Santok Singh for their assistance in the stress rupture tests.

The authors are grateful to Director, National Metallurgical Laboratory, Jamshedpur, India for his kind permission to publish this paper.

\section{REFERENCES}

1. C.J. Moss, P. Barrien and A. Walezynski, International Journal of Pressure Vessels \& Piping, 77 (2-3) 105 (2000).

2. S.T. Tu, .M. Gong and K.B. Yoon, Engineering Failure Analysis, 6(3) 143 (1999).

3. R. Vishwanathan, Damage mechanism and life assessment of high temperature components, ASME International, Metals Park, Ohio 44073, (1989)236 .
4. A.K. Ray, Y.N. Tiwary and S. Chaudhuri, Engineering Failure Analysis, 7(6) 393 (2000).

5. A.K. Ray, Y.N.Tiwary, P.K.Roy, R.K. Sinha and S. Chaudhuri, Journal of the Mechanical Behaviour of Materials , 12.(1) 21 (2001).

6. A.K. Ray, S.K. Sinha, Y.N. Tiwari, J. Swaminathan, G. Das, S. Chaudhuri and R. Singh, Analysis of failed reformer tubes, Engineering Failure Analysis, 10351 (2003).

7. R. Viswanathan, $R$.Dooley and A. Saxena, in: Proceedings of International Conference on Life Assessment and Extension, Vol II, Congress Centre The Hague/The Netherlands (1988) 175.

8. A.K. Ray, Y.N. Tiwari, R.K. Sinha, S.K. Sinha, P.K. Roy, R. Singh and S. Chaudhuri, High Temperature Materials and Processes, 20 (1) 39 (2001).

9. A.K. Ray, P. Kumar, S. Chaudhuri, P.K. Roy, G. Das, S. Ghosh Chowdury, S. Sivaprasad and R.N. Ghosh, investigation report no: NML IR No. TSP (0098), (2000).

10. S. Chaudhuri, Some aspects of creep behaviour of 2.25 Cr-1 Mo steel, Ph.D. Thesis, I.I.T, Kharagpur, (1993). 
